\title{
Dynamic changes to survivin subcellular localization are initiated by DNA damage
}

This article was published in the following Dove Press journal:

OncoTargets and Therapy

I July 2010

Number of times this article has been viewed

\author{
Maritess Gay Asumen' \\ Tochukwu V Ifeacho ${ }^{2}$ \\ Luke Cockerham ${ }^{3}$ \\ Christina Pfandl ${ }^{4}$ \\ Nathan R Wall ${ }^{3}$ \\ 'Touro University's College of \\ Osteopathic Medicine, Vallejo, \\ CA, USA; ${ }^{2}$ University of Southern \\ California, Los Angeles, CA, USA; \\ ${ }^{3}$ Center for Health Disparities \\ Research and Molecular Medicine, \\ Loma Linda University, CA, USA; \\ ${ }^{4}$ Green Mountain Antibodies, \\ Burlington, VT, USA
}

\begin{abstract}
Subcellular distribution of the apoptosis inhibitor survivin and its ability to relocalize as a result of cell cycle phase or therapeutic insult has led to the hypothesis that these subcellular pools may coincide with different survivin functions. The PIK kinases (ATM, ATR and DNA-PK) phosphorylate a variety of effector substrates that propagate DNA damage signals, resulting in various biological outputs. Here we demonstrate that subcellular repartitioning of survivin in MCF-7 cells as a result of UV light-mediated DNA damage is dependent upon DNA damage-sensing proteins as treatment with the pan PIK kinase inhibitor wortmannin repartitioned survivin in the mitochondria and diminished it from the cytosol and nucleus. Mitochondrial redistribution of survivin, such as was recorded after wortmannin treatment, occurred in cells lacking any one of the three DNA damage sensing protein kinases: DNA-PK, ATM or ATR. However, failed survivin redistribution from the mitochondria in response to low-dose UV occurred only in the cells lacking ATM, implying that ATM may be the primary kinase involved in this process. Taken together, this data implicates survivian's subcellular distribution is a dynamic physiological process that appears responsive to UV lightinitiated DNA damage and that its distribution may be responsible for its multifunctionality.
\end{abstract}

Keywords: survivin, PIK kinases, ATM, ATR, DNA-PK

\section{Introduction}

Among the regulators of apoptosis, considerable attention has been focused on the inhibitor of apoptosis protein (IAP) survivin. ${ }^{1-3}$ Survivin is bifunctional as it is implicated in both apoptosis and mitotic regulation and has been shown to reside in the mitochondria, ${ }^{4}$ nucleus and cytosol of tumors, ${ }^{5}$ and proliferating normal cells. ${ }^{6}$ Subcellular distribution and the ability to relocalize as a result of cell cycle phase or therapeutic insult has led to the hypothesis that these subcellular pools may coincide with different survivin functions.

The PIK kinases (ATM, ATR and DNA-PK) phosphorylate a variety of effector substrates that propagate DNA damage signals, ultimately resulting in various biological outputs influencing cell cycle arrest, transcription, DNA repair, and apoptosis. ${ }^{7}$ ATM is activated by DNA double-strand breaks whereas ATR is recruited to single-stranded DNA regions, which arise at stalled replication forks or during the processing of bulky lesions such as UV photoproducts. ${ }^{8}$ Both ATM and ATR share overlapping phosphorylation targets but also have distinct substrates. Most notable, ATR specifically phosphorylates and activates the transducer kinase, Chk1, whereas ATM preferentially phosphorylates Chk2. ${ }^{8,9}$ Tumor cells exposed to DNA damage have been shown to release survivin from their mitochondria in order to counteract cell death. ${ }^{4}$ This pathway 
has been shown to be Chk2-dependent as cells depleted of $\mathrm{Chk} 2$ are unable to release survivin from the mitochondria and become apoptotic. ${ }^{10}$

This study reports a survivin compartmentalization in the mitochondria and enhanced cellular apoptosis following treatment of MCF-7 cells with the pan PIK kinase inhibitor wortmannin. Cells also experience a radiation induced decrease in survivin from all three cellular compartments, mitochondria, nucleus and cytosol, following wortmannin treatment. This finding implies that the PIK kinases may be involved in survivin localization to the mitochondria for apoptosis regulation and to the nucleus for cell cycle arrest phenotypes. Mitochondrial redistribution of survivin, as was recorded after wortmannin treatment, occurred in cells lacking the PIK kinases: ATR and DNA-PK. However, failed survivin redistribution to the nucleus in response to UV radiation occurred only in the cells lacking ATM.

Taken together, this data implicates survivin's subcellular distribution is a dynamic physiological process that is responsive to UV light initiated DNA damage and that its distribution may be responsible for its multifunctionality.

\section{Material and methods}

\section{Cell lines and cultures}

Osteosarcoma ( $\mathrm{SaOS} 2)$, breast carcinoma (MCF7) cell lines were obtained from the American Type Culture Collection (ATCC, Manassas, VA) while M059K (DNA-PK ${ }^{+/+}$), M059J (DNA-PK $\left.{ }^{-/}\right)$, GM02184E $\left(\mathrm{ATM}^{+/+}\right)$, GM03189D $\left(\mathrm{ATM}^{-/-}\right)$ cells were obtained from the Coriell Institute (Camden, NJ). GM847Kd cells produce a dominant negative ATR kinase inactive mutant (ATRkd) under the control of a tet activator, which can be turned on by the addition of doxycycline in the culture media. These cells were a kind gift from Dr. William A. Cliby, Mayo Clinic, Rochester, MN USA.

For the induction of ATRkd expression in GM847Kd cells, doxycycline $(1 \mu \mathrm{g} / \mathrm{ml})$ was added to the medium for 2-4 days before harvesting. Cells were maintained as defined in Dulbecco's modified Eagle's medium (DMEM), McCoy's, RPMI medium 1640 (RPMI) or Iscove's modified Eagle's medium (IMEM) (ATCC) supplemented with 100 units of penicillin, $100 \mathrm{mg} / \mathrm{ml}$ streptomycin, $300 \mathrm{mg}$ of L-glutamine and $10 \%-20 \%$ heat inactivated fetal bovine serum (FBS) (ATCC). Cells were grown at $37^{\circ} \mathrm{C}$ in a humidified atmosphere of $95 \%$ air, $5 \% \mathrm{CO}_{2}$.

Where indicated, cells were exposed to $0,50,100,200$, 300 or $400 \mathrm{~J} / \mathrm{m}^{2} \mathrm{UV}$ irradiation using a Stratalinker 1800 (equipped with standard $254 \mathrm{~nm}$ UV bulbs emitting UVC band energy) (Stratagene, La Jolla, CA). After irradiation, cells were returned to the incubator and harvested at the indicated times. Where indicated, cells were preincubated with Wortmannin (Sigma Chemical Co., St. Louis, MO), dissolved in dimethyl sulfoxide (DMSO) and used at a final concentration of $100 \mathrm{mM}$.

\section{Apoptosis and cell cycle analysis}

Subconfluent cultures of the various cell lines were treated as indicated for 24,48 and 72 hours at $37^{\circ} \mathrm{C}$. Cells were harvested, prepared, and analyzed for DNA content as described previously. ${ }^{11,12}$ DNA content was analyzed using a Becton Dickinson FACScan flow cytometer (Becton Dickinson, San Jose, CA). The distribution of cells in the different phases of the cell cycle was analyzed from DNA histograms using BD CellQuest software (Becton Dickinson and Company, San Jose, CA).

\section{Preparation of nuclear, mitochondrial and cytosolic extracts}

Nuclear, mitochondrial and cytosolic fractions were extracted from cells $\left(5 \times 10^{7}\right.$ to $\left.7 \times 10^{7}\right)$ as has been previously described. ${ }^{4}$ Briefly, extracts were prepared from cells washed in TD buffer (135 mM NaCl, $5 \mathrm{mM} \mathrm{KCl,} 25 \mathrm{mM}$ Tris-Cl, $\mathrm{pH}$ 7.6) and allowed to swell for 10 minutes in ice-cold hypotonic CaRSB buffer (10 mM NaCl, $1.5 \mathrm{mM} \mathrm{CaCl}$, $10 \mathrm{mM}$ Tris-HCl, $\mathrm{pH} 7.5$, plus protease inhibitors). Cells were Dounce-homogenized with 70 strokes using a type B pestle, with addition of MS buffer $(210 \mathrm{mM}$ mannitol, $70 \mathrm{mM}$ sucrose, $5 \mathrm{mM}$ Tris, $\mathrm{pH}$ 7.6) to stabilize mitochondria.

The nuclei and cytosol were separated from each other by centrifugation at $600 \mathrm{~g}$ for 15 minutes at $4{ }^{\circ} \mathrm{C}$. The isolated cytosolic fraction was further centrifuged at $10,000 \mathrm{~g}$ for 25 minutes at $4^{\circ} \mathrm{C}$, and the supernatant was collected. The purity of mitochondrial fractions was examined by immunoblotting with antibodies to mitochondrial Cox-4.

\section{Western blot analysis}

Cells were solubilized, proteins (20-40 $\mu \mathrm{g})$ separated using $12 \%$ and $15 \%$ Bis-Tris polyacrylamide gels, proteins transferred onto polyvinlidene difluoride or nitrocellulose membranes (Millipore) and probed using the following antibodies: mouse monoclonal anti-TATA binding protein (AbCam, Cambridge, MA), rabbit polyclonal anti-survivin (Novus, Littleton, CO), rabbit polyclonal antibodies to ATM, ATR, DNA-PK, VDAC-1 (AbCam), rabbit polyclonal antibodies to GAPDH; and Cox IV (Cell Signaling Technologies, 
Beverly, MA), mouse monoclonal antibodies to $\beta$-actin (AbCam, Cambridge, MA).

Secondary antibodies (IR-Dye-conjugated) were goat anti-rabbit and goat anti-mouse immunoglobulin (LICOR, Lincoln, Nebraska).

Immunoreactive bands were detected using the Odyssey imaging system (LICOR) and quantified using ImageQuant software. Protein quantifications presented in this report were normalized with respect to $\beta$-actin or GAPDH.

\section{Results and discussion}

\section{UV radiation induces survivin protein expression}

One of the goals of this work was to investigate the mechanism by which survivin's intracellular location aids the self-repair response to genotoxic stress, preventing therapy induced apoptosis. One well established feature of the DNA damage response is the slowing or arrest of cell-cycle progression, as a result of what are termed DNA damage "checkpoints", which delay key cell-cycle transitions until repair has occurred. ${ }^{13-15}$ Protein phosphorylation has been implicated in the regulation of cell death pathways, ${ }^{12}$ influencing subcellular localization, ${ }^{16}$ cytoprotection, ${ }^{12,17,18}$ and cell cycle transitions. ${ }^{19,20}$ Survivin phosphorylation on $\mathrm{Thr}^{34}$ by the mitotic kinase $\mathrm{p} 34^{\mathrm{cdc} 2}$ cyclin B1 has been shown to be critical for survivin's function and stability. ${ }^{12,21,22}$

Low dose genotoxic stressors such as Adriamycin (Adria., $100 \mathrm{nM}$ ), Cisplatin (C.P., $3 \mu \mathrm{M})$ and UV $\left(50 \mathrm{~J} / \mathrm{m}^{2}\right)$ arrest MCF-7 cells in the G2/M phase of the cell cycle, while high-dose UV (doses $\geq 100 \mathrm{~J} / \mathrm{m}^{2}$ ) or the tubulin poison Taxol $(2 \mu \mathrm{M})$ induce cellular death (Supplemental Figure 1A). Exposure of MCF-7 cells to low-dose $\left(50 \mathrm{~J} / \mathrm{m}^{2}\right)$ UV radiation resulted in a sustained to enhanced expression of survivin that was also associated with enhanced p53 and p21-dependent cell cycle arrest (Figure 1A, Supplemental Figure 1B). ${ }^{12}$ In contrast, high-dose (100 J/ $\mathrm{m}^{2}$ ) UV radiation treatment resulted in an enhanced $\mathrm{p} 53$ protein expression, no p21 upregulation and a concomitant decline in survivin expression that was not associated with cell cycle arrest but with modest cellular apoptosis (Figure 1A and 1B).

The p53 stability associated survivin reduction may be the direct effect of p53's ability to work as a transcriptional repressor. ${ }^{23}$ However, as survivin's protein expression is never completely absent and we have not sequenced p53, we cannot be certain. In several studies, the transcriptional repression activity of p53 has been implicated in p53-dependent apop- tosis; notable was the finding that deletion of the proline rich domain of p53 renders it competent as a transactivator but unable to induce apoptosis or to repress transcription. ${ }^{24-26}$

We also investigated the effect of UV irradiation on the p53 deficient cell line Saos2 (Figure 1C). Unlike MCF-7 cells, no p53 protein was produced and p21 levels, which were quite high in control, non-UV treated cells, rapidly reduced in a time- and dose-dependent manner. Survivin levels also gradually declined in a dose- and time-dependent manner (Figure C) but were not directly associated with p21 as survivin reduction occurred much slower than did p21. Levels of cell death in these cells increased dramatically compared to MCF-7 cells in a time-and dose-dependent manner (Figure 1D). Interestingly, low-dose UV radiation did not markedly induce cell death in the MCF-7 cells but did in Saos2 cells (Figure 1B and 1D). This is most likely the result of the p53-dependent, p21-dependent cell cycle arrest and concomitant stable upregulation of survivin.

\section{PI3K related kinases and p53 are involved in survivin redistribution}

Tumor cells often become resistant to DNA damage based therapy by releasing survivin from the mitochondria in a p53-independent, but checkpoint kinase 2 (Chk2)-dependent manner. ${ }^{4,10}$

Several PI3K related kinases, including DNA-PK, ATM, and ATR, participate in DNA damage responsive pathways. ${ }^{7}$ In order to ascertain their roles in enhanced survivin expression levels after UV radiation induced DNA damage, cells were treated with the pan-PIK kinase inhibitor wortmannin. Wortmannin treatment alone did not alter apoptosis levels in either MCF-7 or Saos2 cells as can be seen in the $0 \mathrm{~J} / \mathrm{m}^{2}$ treatment control groups (Figure 1B and 1D). However, upon treating both cell lines with 50 or $100 \mathrm{~J} / \mathrm{m}^{2} \mathrm{UV}$, a timedependent increase in cell death was observed in both cell lines. Survivin from MCF-7 cells treated with wortmannin compartmentalized in the mitochondria (Figure 2B) and was diminished from the cytosol (Figure 2A) and nucleus (Figure 2C). However, UV (50 J/ $\mathrm{m}^{2}$ ) light mediated $\mathrm{G} 2 / \mathrm{M}$ growth arrest of MCF-7 cells led to enhanced total cellular survivin (Figure 1) as well as partitioning of this survivin from the cytosol to the mitochondria (Figure 2B) and nucleus (Figure 2C). Wortmannin prohibited this repartitioning after lowdose UV treatment. 
A

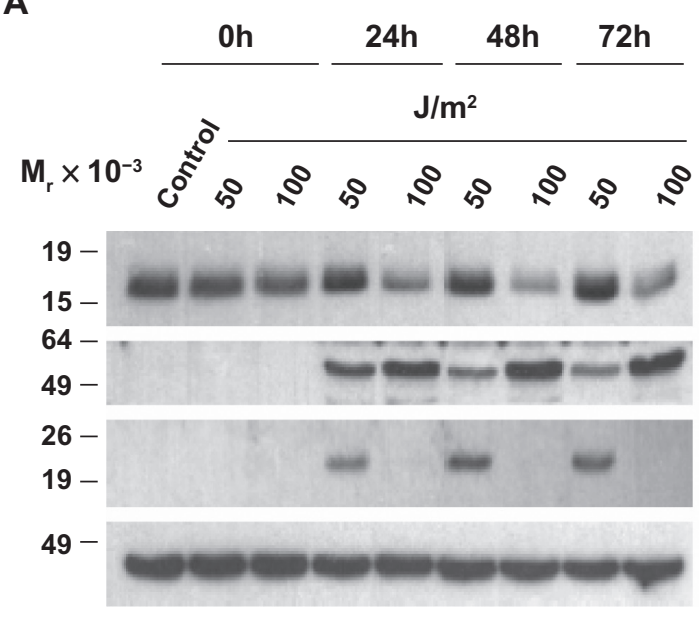

B

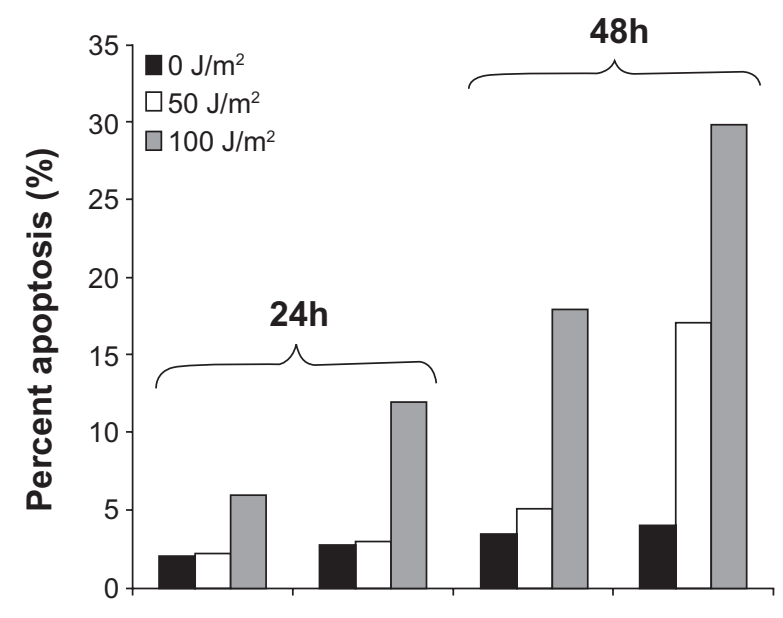

C

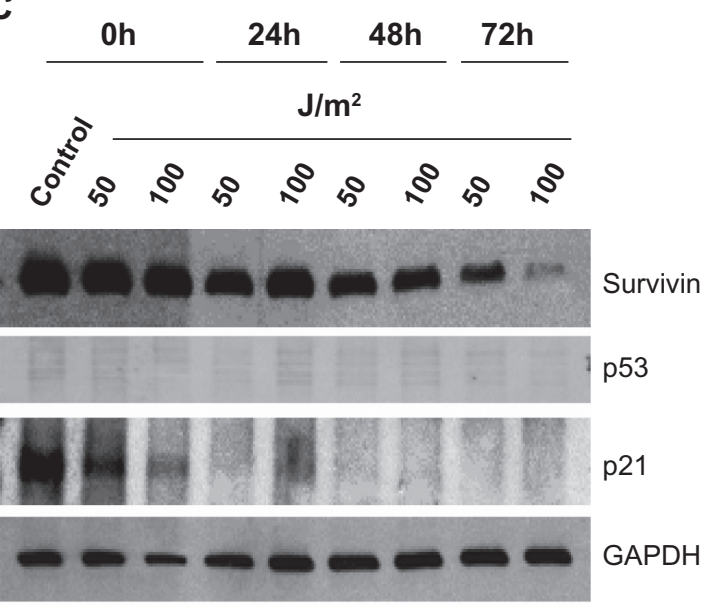

D

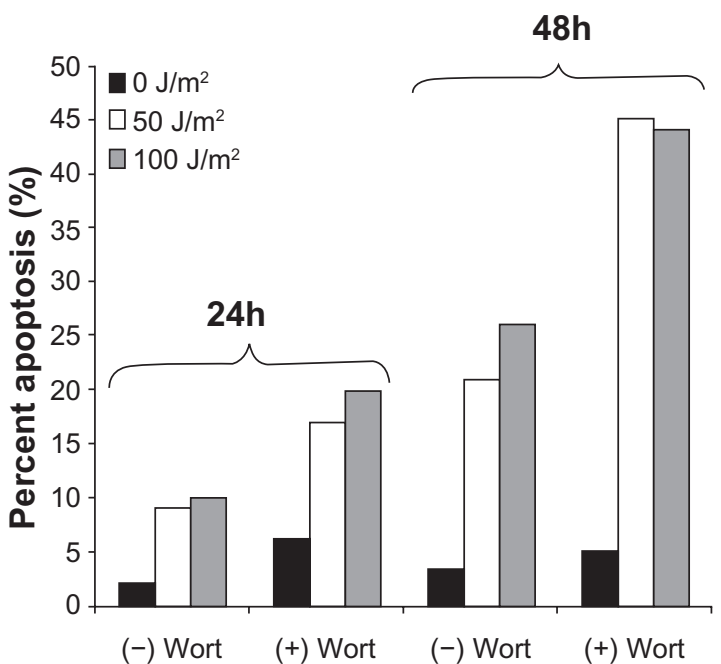

Figure I UV radiation induced apoptosis is enhanced by wortmannin's inhibition of PI3K related kinases. MCF-7 (A) and Saos 2 (C) cells exposed to 50 or I00 J/m² UV for 24 , 48, or 72 hours were analyzed by Western blotting. MCF-7 (B) and Saos2 (D) cells were grown in the presence or absence of wortmannin, irradiated as above and analyzed for DNA content after 24 and 48 hours. The percentage of cells with hypodiploid DNA content is indicated.

In Saos 2 cells, a UV dose-dependent reduction in survivin protein (Figure 1C) was associated with survivin reduction from all three compartments, cytosol, mitochondria and nucleus (Figure 2A-2C). In both cell lines, $100 \mathrm{~J} / \mathrm{m}^{2} \mathrm{UV}$ combined with wortmannin resulted in survivin reduction from all three compartments (Figure 2A-2C) and enhanced apoptosis in both cell lines (Figure 1B and 1D). Wortmannin's inability to enhance the apoptotic killing of $100 \mathrm{~J} / \mathrm{m}^{2}$ over that of $50 \mathrm{~J} / \mathrm{m}^{2} \mathrm{UV}$ in Saos2 cells (Figure 1D) did not surprise us as survivin was not repartitioned to nucleus, cytosol or mitochondria (Figure 2). It has been shown that ionizing radiation modulates survivin independently of gene expression or the $\mathrm{G} 2 / \mathrm{M}$ checkpoint, ${ }^{10}$ and that the treating of MCF-7 cells with ionizing radiation induced a discharge of mitochondrial survivin that coincided with increased cytosolic survivin.

It has already been shown that survivin's cytoprotective function involved the discharge of mitochondrial survivin to the cytosol where it prevents caspase activation and inhibits apoptosis. ${ }^{4}$ Interestingly and contrary to these two reports, ${ }^{4,10}$ UV treated Saos 2 cells experienced a notable mitochondrial release (Figure 2B) of survivin that did not result in a stable cytosolic accumulation. Instead, survivin depletion was recorded from all three subcellular pools.

These findings imply that the PIK kinase-dependent p53 pathway may be involved in survivin relocalization to the mitochondria for apoptosis regulation and the nucleus for cell cycle arrest phenotypes. 


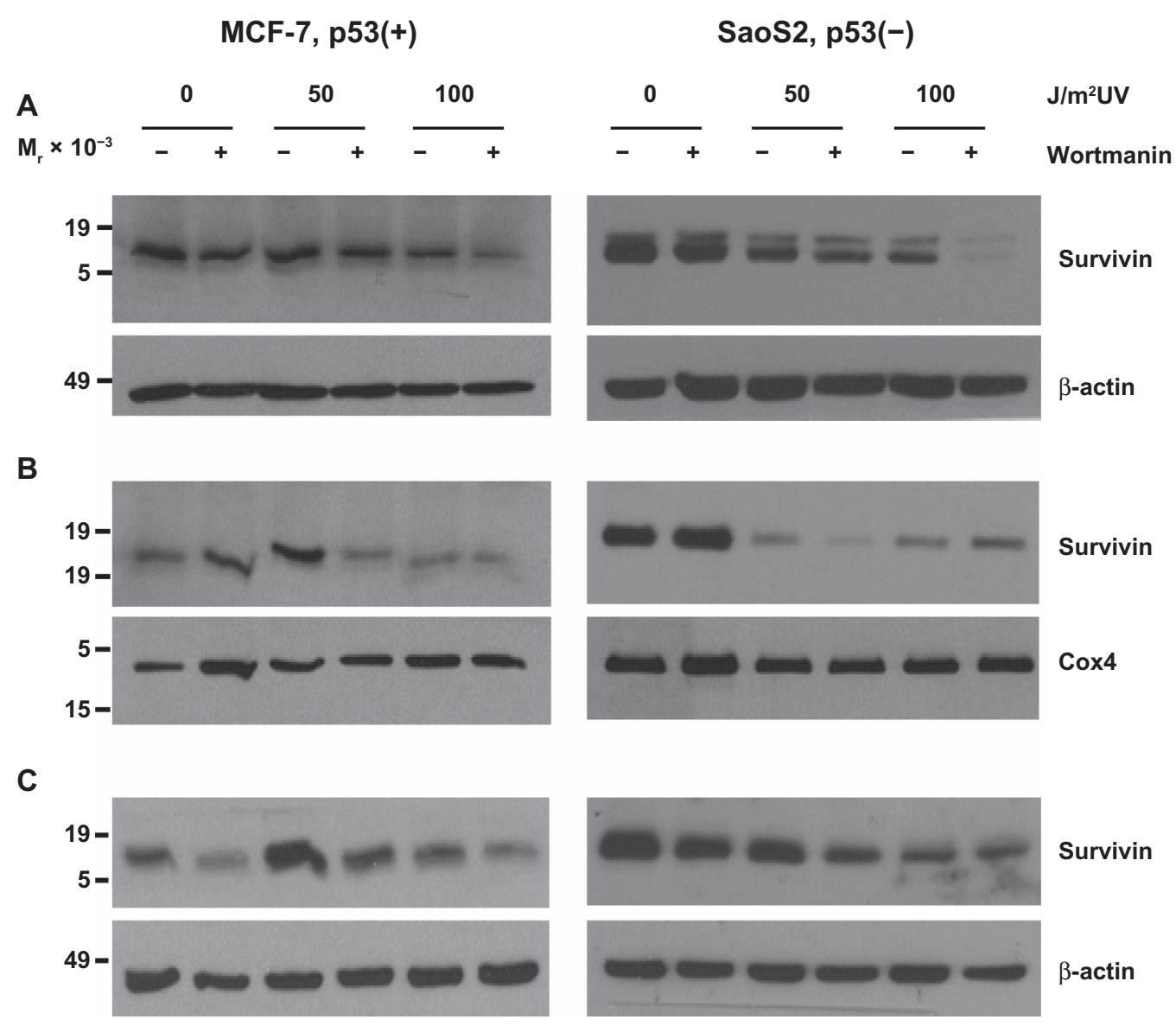

Figure 2 UV radiation's repartitioning of survivin from the cytosol to the mitochondria and nucleus is reduced after wortmannin treatment in p 53 expressing MCF-7 cells. MCF-7 and Saos2 cells, exposed to 50 or $100 \mathrm{~J} / \mathrm{m}^{2}$ UV for 24 hours were subcellularly fractionated into cytosol (A), mitochondria (B) and nuclear (C) fractions and analyzed by Western blotting.

\section{Loss of $\mathrm{PI} 3 \mathrm{~K}$ related kinases increases cellular apoptotic response to UV irradiation}

As shown in Figure 2, wortmannin blocked survivin's redistribution in MCF-7 cells, suggesting that one or more PI3K related kinases are involved in these UV irradiation redistribution events.

To explore which PI3K related kinase(s) is/are required for Survivin redistribution within the UV treated cell, we used a panel of cell lines that were either proficient or deficient in DNA-PK, ATM or ATR. DNA-PK and ATM deficiency rendered the cells noticeably more sensitive to UV induced apoptosis (Figure 3) in both a time- and dose-dependent manner. Cells that had been made kinase dead for ATR $^{27}$ exhibited little more than a modest enhanced cell death.

These are consisten with the known role of these proteins in sensing DNA damage, as has been well described, ${ }^{7,28}$ and are also consistent with those previously shown in these cells with regard to UV induced damage. ${ }^{27}$

\section{UV radiation induces defining changes in survivin protein expression}

Exposure of DNA-PK ${ }^{+/+} \mathrm{M} 059 \mathrm{~K}$ fibroblast cells to low-dose $\left(50 \mathrm{~J} / \mathrm{m}^{2}\right)$ UV radiation resulted in a sustained expression of survivin that was associated with enhanced p53 and p21 protein expression similar to what was recorded in MCF-7 cells (Figure 4A).

In contrast, high-dose $\left(100 \mathrm{~J} / \mathrm{m}^{2}\right)$ UV radiation treatment resulted in a reduced $\mathrm{p} 53$ and $\mathrm{p} 21$ protein expression and a concomitant decline in survivin expression (Figure 4A). DNA-PK ${ }^{-/-}$M059J cells irradiated with either low- or high-dose UV responded with a time- and dosedependent reduction in survivin, p53 and p21 (Figure 4A) with levels of cell death in these cells increasing dramatically compared with their DNA-PK ${ }^{+/+} \mathrm{M} 059 \mathrm{~K}$ counterparts (Figure 3).

Low- and high-dose UV radiation on $\mathrm{ATM}^{+/+}$ GM02184E and $\mathrm{ATM}^{-/-}$GM03189D fibroblast cells was investigated with results mirroring more the Saos2 cells 

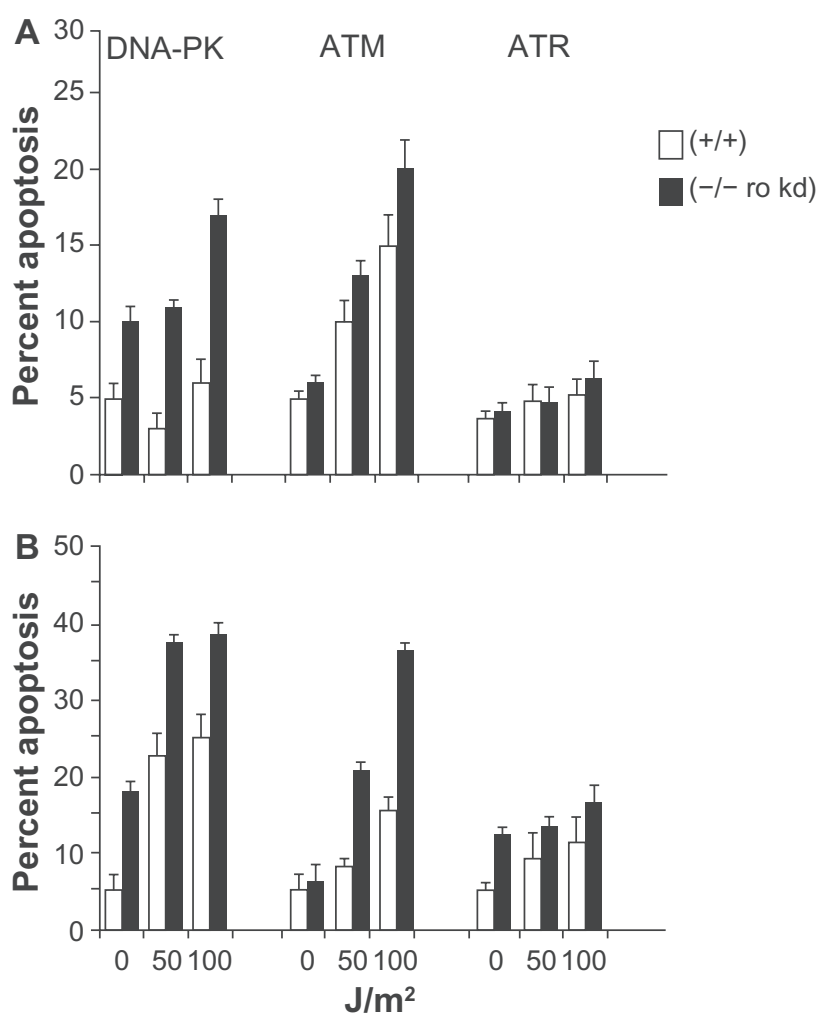

Figure 3 Loss of DNA-PK, ATM and expression of a kinase dead (kd) ATR renders cells sensitive to UV radiation. M059K (DNA-PK ${ }^{++}$), M059] (DNA-PK ${ }^{-1-}$ ), GM02184E $\left(\mathrm{ATM}^{+/+}\right)$, GM03189D $\left(\mathrm{ATM}^{-/-}\right)$, GM847 $\left(\mathrm{ATR}^{+/+}\right)$and GM847Kd (ATR kinase dead) were exposed to 50 or $100 \mathrm{~J} / \mathrm{m}^{2} \mathrm{UV}$ and analyzed for DNA content after (A) 24 and (B) 48 hours. The percentage of cells with hypodiploid DNA content is indicated.

with and without wortmannin than the DNA-PK cell lines. High and low dose radiation treatments resulted in time dependent cellular reduction in survivin, p53 and p21 levels with modest levels of apoptotic protection measured but increasing from $24 \mathrm{~h}$ to $48 \mathrm{~h}$ after UV irradiation (Figure 4B and Figure 3). Interestingly, GM847/ ATRkd- $\left(\mathrm{ATR}^{+++}\right)$cells were UV irradiated, survivin, $\mathrm{p} 53$, and p21 levels responded most similar to how MCF-7 cells without wortmannin and the DNA-PK ${ }^{+/+}$M059K fibroblast cells had (Figure 4C). Survivin protein levels increased after $50 \mathrm{~J} / \mathrm{m}^{2} \mathrm{UV}$ as did $\mathrm{p} 21$. P53 levels remains mostly unchanged. GM837/ATRkd+(ATR $\left.{ }^{--}\right)$cells showed an increase in survivin and $\mathrm{p} 53$ levels and a complete loss of $\mathrm{p} 21$ expression after UV treatments (Figure 4C). Cells expressing the mutant form of ATR(ATRkd+) were not more susceptible to UV DNA damage induced apoptosis even after 48 hours (Figure 3).

Cellular redistribution of survivin, such as was recorded after wortmannin treatment, occurred in cells lacking any one of the three DNA damage-sensing protein kinases: DNA-PK, ATM or ATR (Figure 5). However, failed survivin redistribution from the mitochondria in response to $50 \mathrm{~J} / \mathrm{m}^{2} \mathrm{UV}$ occurred only in the cells lacking ATM (Figure 5B). ATM preferentially phosphorylates Chk2, 8,9 and mitochondria release of survivin to counteract DNA damage induced cell death has been shown to be Chk2-dependent, ${ }^{10}$ further implying that ATM may be the primary kinase involved in this process.

Failed survivin redistribution from the nucleus in response to $50 \mathrm{~J} / \mathrm{m}^{2} \mathrm{UV}$ occurred in the cells lacking DNA-PK and those expressing the kinase dead ATR (Figure 5C), implying that DNA-PK and ATR may be the primary kinases involved in this process as well as possible overlapping functions between these two kinases.

Interestingly, cells lacking DNA-PK had a significant increase in cytosolic survivin protein (Figure 5A) that was not associated with reduced cellular apoptosis (Figure 3). It is also probable that this survivin redistribution is p53-dependent as similar experiments performed in the p53-deficient Saos-2 cell line, failed to redistribute as was recorded in the MCF-7 cells and those cells lacking DNAPK, ATM or ATR.

Based upon our results, it is likely that loss of any one of these kinases may lead to survivin dysregulation and an increased risk of cancer. It will be of significant interest to investigate further the role these kinases play in cancer and its onset given cancer's genomic instability. The work we show here was mostly accomplished in fibroblast cell lines that inherently have a more stable genome than do cancer cells.

\section{Conclusion}

We have shown the important discovery that survivin's cellular transport is modified depending upon the presence or absence of specific DNA damage-sensing proteins like DNA-PK, ATM and ATR.

Our data show that survivin is differentially expressed, and localized as a result of UV light initiated DNA damage and that its localization changes from one subcellular locale to another as a result of the presence or absence of PIK kinases.

In addition, our data suggests that there might be a common underlying mechanism by which ATM, ATR and DNA-PK detect and transduce UV damage signals and in order to unravel a possible role for survivin in this pathway, the ability to eliminate more than one of the DNA damage-sensing proteins will be necessary. The overall underlying mechanism may also involve interactions with other DNA repair or maintenance proteins or function through a common effector such as p53. Furthermore, we have shown that these three DNA damage 
$(+/+)$

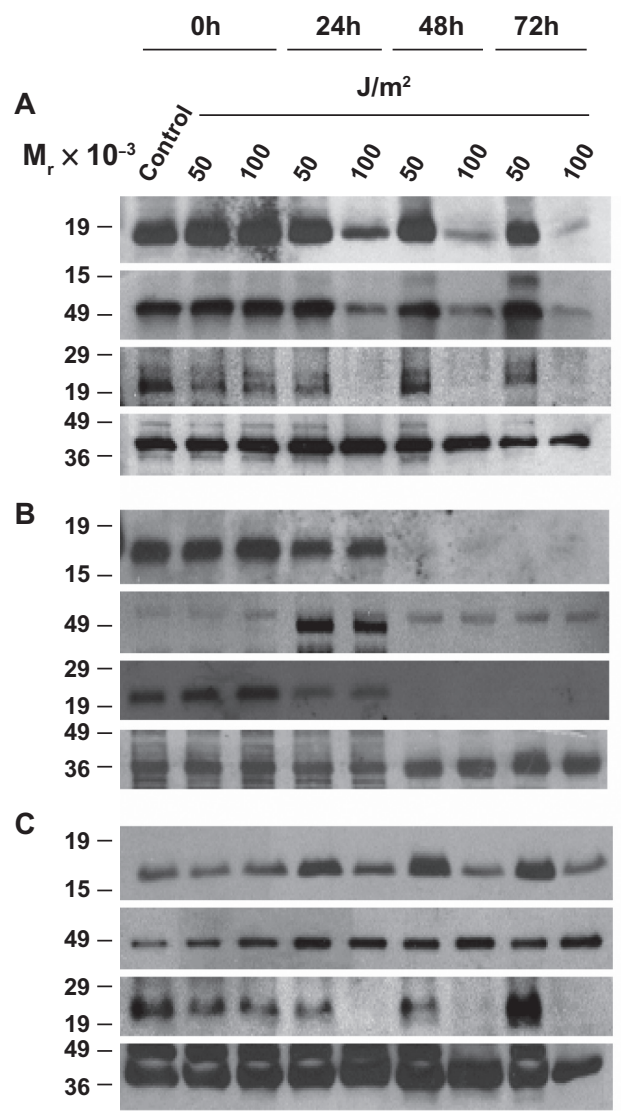

$(-/-o r k d)$

$\frac{0 \mathrm{~h}}{\mathrm{~J} / \mathrm{m}^{2}} \frac{24 \mathrm{~h}}{48 \mathrm{~h}} \frac{72 \mathrm{~h}}{\mathrm{~s}}$
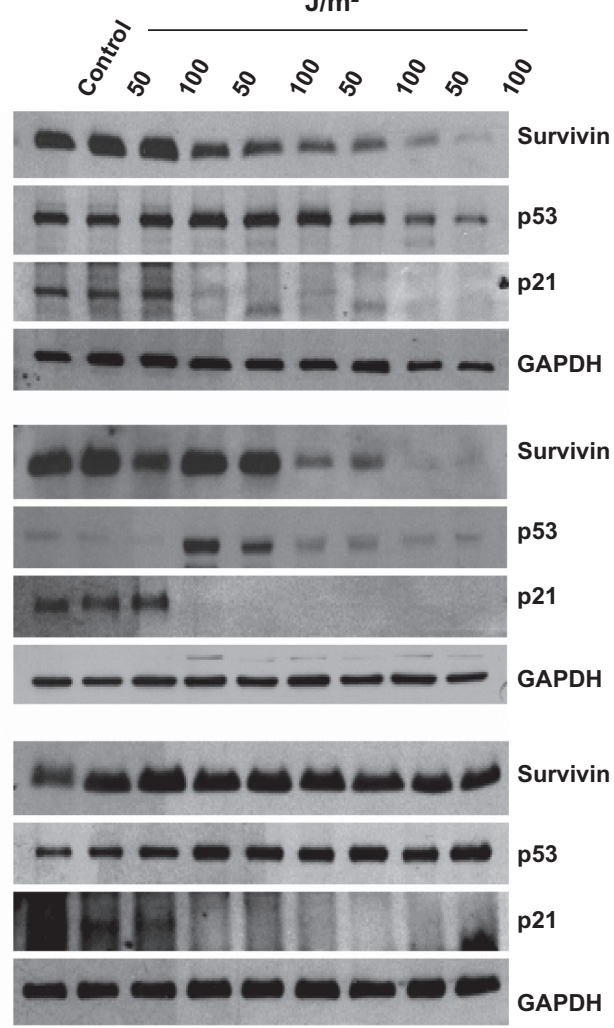

Figure 4 Survivin, $\mathrm{p} 53$ and p2I, after UV radiation, are differentially expressed in PI3K related kinase competent versus incompetent cells. A) M059K (DNA-PK ${ }^{+/+}$), M059J (DNA-PK $\left.{ }^{-1}\right)$, B) GM02184E $\left(\right.$ ATM $\left.^{+++}\right)$, GM03189D $\left(\right.$ATM $\left.^{-1}\right)$, C) GM847 $\left(\right.$ ATR $^{++}$) and GM847Kd (ATR kinase dead) were exposed to 50 or $100 \mathrm{~J} / \mathrm{m}^{2}$ UV and analyzed by Western blotting after 24,48 , and 72 hours.

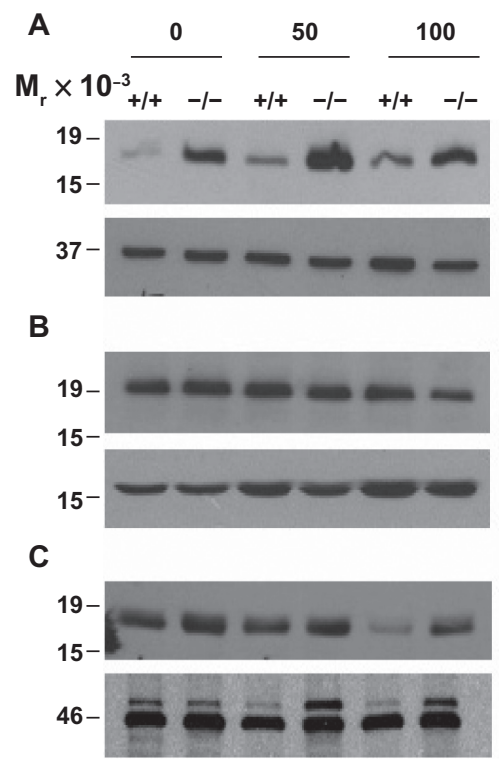

DNA-PK
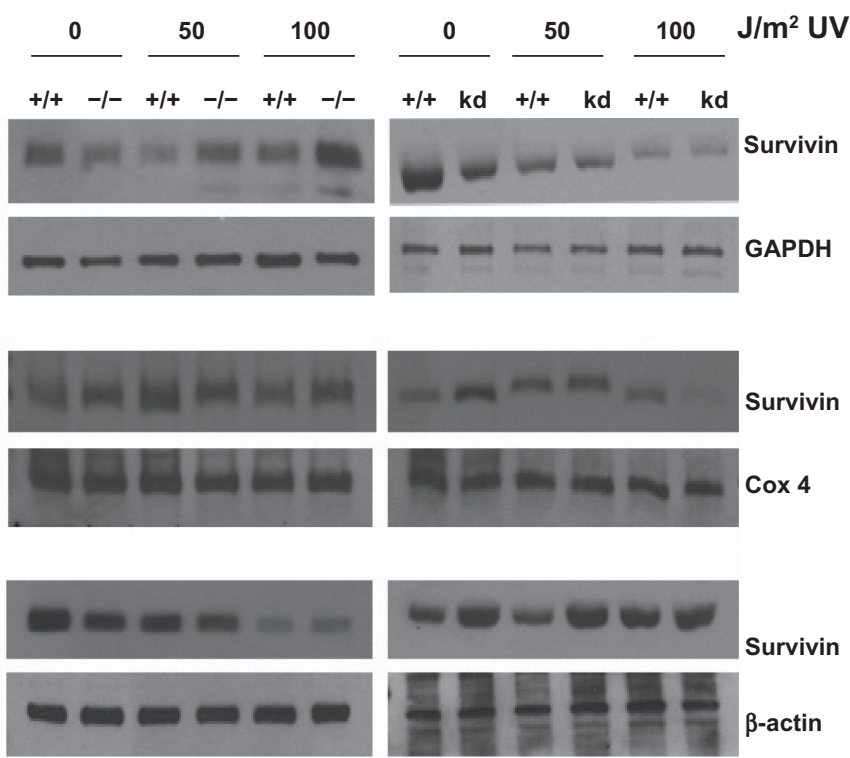

ATM

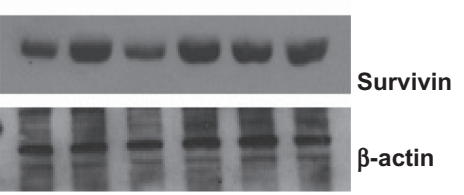

ATR

Figure 5 UV radiation repartitions survivin from the cytosol to the mitochondria and nucleus. M059K (DNA-PK ${ }^{++/}$), M059J (DNA-PK ${ }^{-1-}$ ), GM02I84E (ATM ${ }^{+/+}$), GM03।89D $\left(\right.$ ATM $\left.^{--}\right)$, GM847 (ATR ${ }^{++}$) and GM847Kd (ATR kinase dead), exposed to 50 or $100 \mathrm{~J} / \mathrm{m}^{2}$ UV for 24 hours were subcellularly fractionated into cytosol (A), mitochondria (B) and nuclear (C) fractions and analyzed by Western blotting. 
sensors can interact with each other directly or indirectly, and regulate the activities of each other.

These findings are further confirmed by the differences observed between the genetically modified cell lines and the cells treated with the non-specific pan-PIK kinase inhibitor wortmannin.

Consistent with survivin's association with unfavorable clinicopathological parameters, trafficking survivin throughout the tumor cell could potentially be responsible for driving the aggressive status of the tumor, prohibiting or minimizing therapeutic results. Thus, treatment of a tumor, using modalities that can inhibit one or more of these sensors may prove useful in the treatment of cancer.

Many questions remain unanswered regarding the cellular response to DNA damage. How a cell decides to choose between the repair of damaged DNA and the initiation of apoptosis is just one of those questions.

It is our belief that how the multifunctional protein survivin is activated and then trafficked within the cell may play an important role in these decisions. The continued elucidation of survivin's role within these pathways will continue to challenge our future research.

\section{Acknowledgment}

The author's would like to thank especially, Dr. William A. Cliby (Mayo Clinic, Rochester, MN USA) for the kind gift of the GM 847kd fibroblast cells. Grant Support: NCMHD Project EXPORT Program 5P20MD001632/Project 3 (N.R. Wall). Funding was also obtained as part of a start-up package from Loma Linda University's Center for Molecular Biology and Gene Therapy, now the Center for Health Disparities Research and Molecular Medicine (NRW) and a National Merit Test Bed (NMTB) award sponsored by the Department of the Army under Cooperative Agreement Number DAMD17-97-2-7016 (NRW).

\section{Disclosure}

The authors declare that they have no competing interests.

\section{References}

1. Li F, Ambrosini G, Chu EY, et al. Control of apoptosis and mitotic spindle checkpoint by survivin. Nature. 1998;396:580-584.

2. Altieri DC. Survivin, cancer networks and pathway-directed drug discovery. Nat Rev Cancer. 2008;8:61-70.

3. Altieri DC. New wirings in the survivin networks. Oncogene. 2008;27:6276-6284.

4. Dohi T, Beltrami E, Wall NR, et al. Mitochondrial survivin inhibits apoptosis and promotes tumorigenesis. J Clin Invest. 2004;114:1117-1127.

5. Fortugno P, Wall NR, Giodini A, et al. Survivin exists in immunochemically distinct subcellular pools and is involved in spindle microtubule function. J Cell Sci. 2002;115:575-585.
6. Li F. Survivin study: what is the next wave? J Cell Physiol. 2003;197: 8-29.

7. Yang J, Yu Y, Hamrick HE, Duerksen-Hughes PJ. ATM, ATR and DNA-PK: initiators of the cellular genotoxic stress responses. Carcinogenesis. 2003;24:1571-1580.

8. StiffT, Walker SA, Cerosaletti K, et al. ATR-dependent phosphorylation and activation of ATM in response to UV treatment or replication fork stalling. EMBO J. 2006;25:5775-5782.

9. Jazayeri A, Falck J, Lukas C, et al. ATM- and cell cycle-dependent regulation of ATR in response to DNA double-strand breaks. Nat Cell Biol. 2006;8:37-45.

10. Ghosh JC, Dohi T, Raskett CM, et al. Activated checkpoint kinase 2 provides a survival signal for tumor cells. Cancer Res. 2006;66: 11576-11579.

11. Li F, Ackermann EJ, Bennett CF, et al. Pleiotropic cell-division defects and apoptosis induced by interference with survivin function. Nat Cell Biol. 1999;1:461-466.

12. Wall NR, O'Connor DS, Plescia J, et al. Suppression of survivin phosphorylation on $\mathrm{Thr} 34$ by flavopiridol enhances tumor cell apoptosis. Cancer Res. 2003;63:230-235.

13. Rouse J, Jackson SP. Interfaces between the detection, signaling, and repair of DNA damage. Science. 2002;297:547-551.

14. Lowndes NF, Murguia JR. Sensing and responding to DNA damage. Curr Opin Genet Dev. 2000;10:17-25.

15. Abraham RT. Cell cycle checkpoint signaling through the ATM and ATR kinases. Genes Dev. 2001;15:2177-2796.

16. Zha J, Harada H, Yang E, et al. Serine phosphorylation of death agonist BAD in response to survival factor results in binding to 14-3-3 not BCL-X(L). Cell. 1996;87:619-628.

17. Ling YH, Tornos C, Perez-Soler R. Phosphorylation of Bcl-2 is a marker of M phase events and not a determinant of apoptosis. J Biol Chem. 1998;273:18984-18991.

18. Scatena CD, Stewart ZA, Mays D, et al. Mitotic phosphorylation of Bcl-2 during normal cell cycle progression and Taxol-induced growth arrest. J Biol Chem. 1998;273:30777-30784.

19. Yamamoto K, Ichijo H, Korsmeyer SJ. BCL-2 is phosphorylated and inactivated by an ASK1/Jun N-terminal protein kinase pathway normally activated at G(2)/M. Mol Cell Biol. 1999;19:8469-8478.

20. Furukawa Y, Iwase S, Kikuchi J, et al. Phosphorylation of Bcl-2 protein by $\mathrm{CDC} 2$ kinase during $\mathrm{G} 2 / \mathrm{M}$ phases and its role in cell cycle regulation. J Biol Chem. 2000;275:21661-21667.

21. O'Connor DS, Grossman D, Plescia J, et al. Regulation of apoptosis at cell division by $\mathrm{p} 34 \mathrm{cdc} 2$ phosphorylation of survivin. Proc Natl Acad Sci U S A. 2000;97:13103-13107.

22. O'Connor DS, Wall NR, Porter AC, Altieri DC. A p34(cdc2) survival checkpoint in cancer. Cancer Cell. 2002;2:43-54.

23. Hoffman WH, Biade S, Zilfou JT, et al. Transcriptional repression of the anti-apoptotic survivin gene by wild type p53. J Biol Chem. 2002; 277:3247-3257.

24. Sakamuro D, Sabbatini P, White E, Prendergast GC. The polyproline region of p53 is required to activate apoptosis but not growth arrest. Oncogene. 1997;15:887-898.

25. Walker KK, Levine AJ. Identification of a novel p 53 functional domain that is necessary for efficient growth suppression. Proc Natl Acad Sci US A. 1996;93:15335-15340.

26. Venot C, Maratrat M, Dureuil C, et al. The requirement for the $\mathrm{p} 53$ proline-rich functional domain for mediation of apoptosis is correlated with specific PIG3 gene transactivation and with transcriptional repression. EMBO J. 1998;17:4668-4679.

27. Cliby WA, Roberts CJ, Cimprich KA, et al. Overexpression of a kinaseinactive ATR protein causes sensitivity to DNA-damaging agents and defects in cell cycle checkpoints. EMBO J. 1998;17:159-169.

28. Burdak-Rothkamm S, Rothkamm K, Prise KM. ATM acts downstream of ATR in the DNA damage response signaling of bystander cells. Cancer Res. 2008;68:7059-7065. 


\section{Supplement}
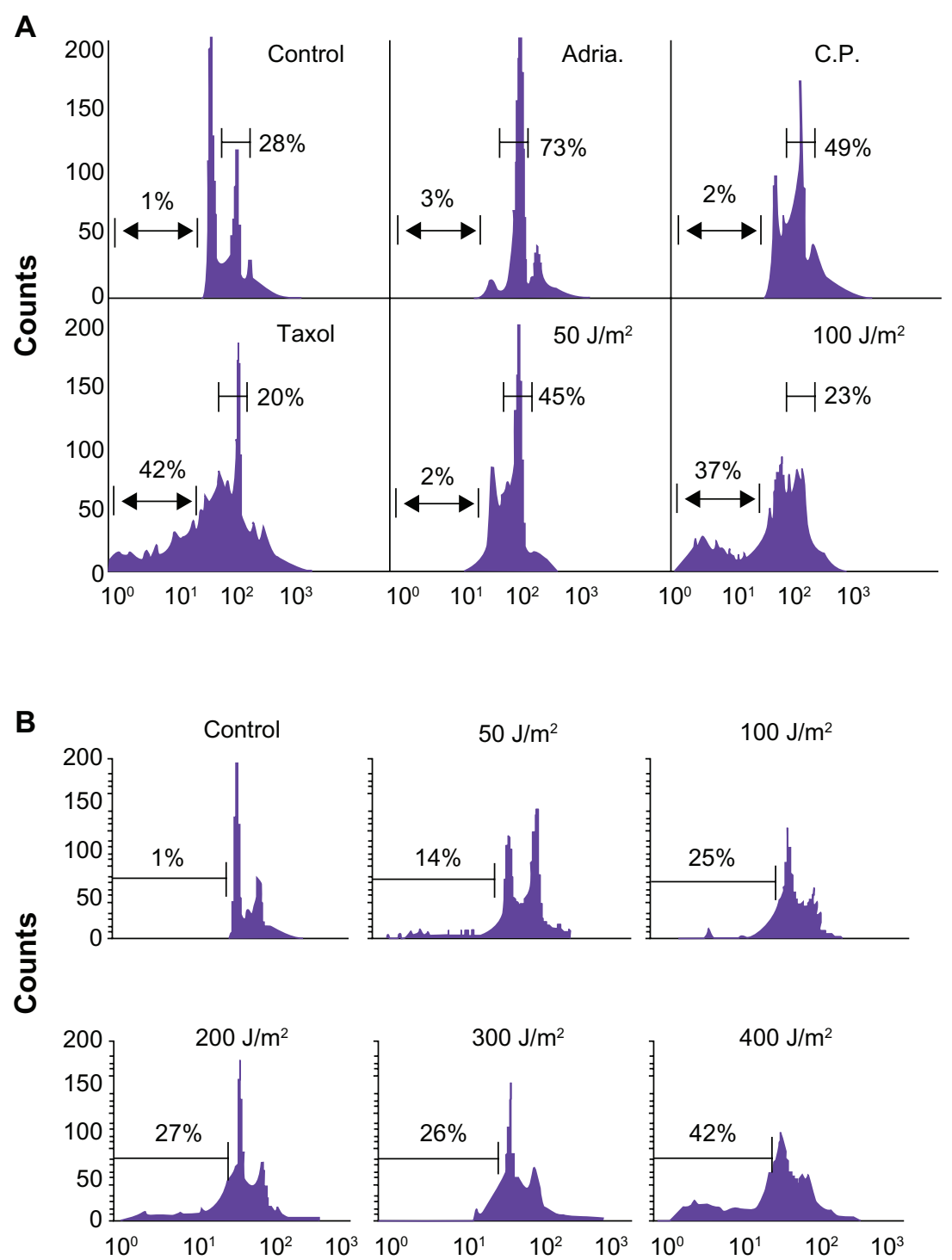

Supplemental Figure I (A) Low dose genotoxic stressors such as Adriamycin (Adria., $100 \mathrm{nM}$ ), Cisplatin (C.P., $3 \mathrm{mM}$ ) and UV (50 J/m²) arrest MCF-7 cells in the G2/M phase of the cell cycle while high-dose UV (doses $\geq 100 \mathrm{~J} / \mathrm{m}^{2}$ ) or the tubulin poison Taxol $(2 \mathrm{mM})$ induce cellular death. (B) Breast carcinoma MCF-7 cells were irradiated with 50-400 J/m² UV under minimal IX PBS. PBS was immediately removed and complete culture medium was added. After 24 hours, cells were harvested and analyzed for DNA content by propidium iodide staining and flow cytometry. Percentages of apoptotic cells with hypodiploid (sub-GI) DNA content are indicated per each condition tested. Data are representative of one of two independent experiments with comparable results.

\section{Publish your work in this journal}

OncoTargets and Therapy is an international, peer-reviewed, open access journal focusing on the pathological basis of all cancers, potential targets for therapy and treatment protocols employed to improve the management of cancer patients. The journal also focuses on the impact of management programs and new therapeutic agents and protocols on

\section{Dovepress}

patient perspectives such as quality of life, adherence and satisfaction. The manuscript management system is completely online and includes a very quick and fair peer-review system, which is all easy to use. Visit http://www.dovepress.com/testimonials.php to read real quotes from published authors. 